\title{
Maternal adiposity, smoking, and thyroid function in early pregnancy
}

\author{
Stine Linding Andersen (1) 1,2, Louise Knøsgaard ${ }^{1,2}$, Aase Handberg ${ }^{1,2}$, Peter Vestergaard ${ }^{2,3,4}$ and Stig Andersen ${ }^{2,5}$ \\ 'Department of Clinical Biochemistry, Aalborg University Hospital, Aalborg, Denmark \\ 2Department of Clinical Medicine, Aalborg University, Aalborg, Denmark \\ ${ }^{3}$ Department of Endocrinology, Aalborg University Hospital, Aalborg, Denmark \\ ${ }^{4}$ Steno Diabetes Center North Jutland, Aalborg University Hospital, Aalborg, Denmark \\ ${ }^{5}$ Department of Geriatrics, Aalborg University Hospital, Aalborg, Denmark
}

Correspondence should be addressed to S L Andersen: stine.a@rn.dk

\begin{abstract}
Objective: A high activity of the deiodinase type 2 has been proposed in overweight, obese, and smoking pregnant women as reflected by a high triiodothyronine

(T3)/thyroxine (T4) ratio. We speculated how maternal adiposity and smoking would associate with different thyroid function tests in the early pregnancy.

Design: Cross-sectional study within the North Denmark Region Pregnancy Cohort. Methods: Maternal thyroid-stimulating hormone (TSH), total T4 (TT4), total T3 (TT3), free T4 (fT4), and free T3 (fT3) were measured in stored blood samples (median gestational week 10) by an automatic immunoassay. Results were linked to nationwide registers, and live-birth pregnancies were included. The associations between maternal adiposity (overweight or obese), smoking, and log-transformed TSH, fT3/fT4 ratio, and TT3/TT4 ratio were assessed using multivariate linear regression and reported as adjusted exponentiated $\beta$ coefficient (a $\beta$ ) with $95 \% \mathrm{Cl}$. The adjusted model included maternal age, parity, origin, week of blood sampling, and diabetes.

Results: Altogether 5529 pregnant women were included, and 40\% were classified with adiposity, whereas $10 \%$ were smoking. Maternal adiposity was associated with higher TSH (a 1.13 (95\% Cl 1.08-1.20)), whereas maternal smoking was associated with lower TSH in the early pregnancy $(0.875(0.806-0.950))$. Considering the T3/T4 ratio, both maternal adiposity (fT3/fT4 ratio: 1.06 (1.05-1.07); TT3/TT4 ratio: 1.07 (1.06-1.08)) and smoking (fT3/fT4 ratio: 1.07 (1.06-1.09); TT3/TT4 ratio: 1.10 (1.09-1.12)) were associated with a higher ratio.

Conclusions: In a large cohort of Danish pregnant women, adiposity and smoking showed opposite associations with maternal TSH. On the other hand, both conditions were associated with a higher T3/T4 ratio in early pregnancy, which may reflect altered deiodinase activity.
\end{abstract}
Key Words
- thyroid
- pregnancy
- obesity
- overweight
- deiodinase

Endocrine Connections (2021) 10, 1125-1133

\section{Introduction}

Maternal thyroid function in early pregnancy is a debated matter $(1,2)$. The role of thyroid hormones in fetal brain development has long drawn ample attention to the potential adverse consequences of abnormal maternal thyroid function in pregnancy $(3,4)$.
However, uncertainties prevail on the definition of thyroid disease in pregnant women and on the role of smaller deviations in maternal thyroid function $(3,4)$. It has long been recognized that the pregnant state influences maternal physiology considerably necessitating https://ec.bioscientifica.com https://doi.org/10.1530/EC-21-0376 (c) 2021 The authors Published by Bioscientifica Ltd
This work is licensed under a Creative Commons Attribution-NonCommercial-NoDerivatives 4.0 denternationab bicense.ifica.com at 04/26/2023 01:56:59AM 
pregnancy-specific reference ranges for thyroid function tests $(5,6)$. Some of the well-known physiological effects in pregnancy include the estrogen-mediated increase in thyroxine-binding globulin (TBG) and the thyroidstimulating effect of human chorionic gonadotropin (hCG). What remains less certain is how pregnancy affects the metabolism of thyroid hormones via the iodothyronine deiodinases types 1, 2, and 3 (D1, D2, and D3).

D2 and D3 are expressed in placenta throughout pregnancy, however, with the highest enzyme activity in the early pregnancy weeks $(7,8)$. D2 catalyzes the conversion of thyroxine (T4) to triiodothyronine (T3), and a high enzyme activity is reflected by a high T3/T4 ratio $(7,8)$. D3 inactivates thyroid hormones by catalyzing the conversion of T3 to reverse T3 (rT3), and a high enzyme activity is reflected by a high rT3/T3 ratio. The high D3 activity from early pregnancy is thought to protect the fetus against excessive levels of thyroid hormones $(3,7)$, but aspects remain uncertain on the role and impact of the different deiodinases in pregnancy.

It is an intriguing finding that non-thyroidal characteristics possibly via an effect on the activity of the deiodinases may influence the levels of thyroid hormones (9). Adiposity and smoking are some of the major threats to public health and common patient characteristics in pregnant and non-pregnant women $(10,11)$. In nonpregnant individuals, a higher activity of the D2 as reflected by a higher T3/T4 ratio has been proposed in overweight and obese individuals with a concomitant decrease in the ratio after weight loss (12). On the other hand, most studies found high T3 and high T4 in smokers (13). In pregnant women, studies have indicated that both maternal adiposity and smoking may be associated with a high T3/T4 ratio $(14,15)$. More evidence is needed to scrutinize how the physiological alterations in pregnancy, in combinations with individual non-thyroidal factors, associate with maternal thyroid function in the early pregnancy.

We aimed to investigate the association between maternal adiposity (overweight or obese) and smoking in pregnancy and a series of thyroid function tests performed in early pregnancy using stored blood samples from the North Denmark Region Pregnancy Cohort (NDRPC) and linkage to Danish nationwide health registers.

\section{Materials and methods}

The study is a cross-sectional design performed within the NDRPC. The NDRPC is a large biobank including stored blood samples from pregnant women in the North Denmark Region $(5,6)$. The blood samples were drawn as part of nationwide screening for chromosomal anomalies in Denmark from 2011 to 2013, and serum residues from these samples were stored at $-80^{\circ} \mathrm{C}$ in a biobank and used for the measurement of maternal thyroid function parameters. The biochemical measurements were then linked to information in Danish nationwide health registers. The study was approved by the North Denmark Region Committee on Health Research Ethics (20150015) and the Danish Data Protection Agency (2008-58-0028).

Measurement of thyroid function parameters was performed using automatic immunoassays in the Departments of Clinical Biochemistry in the North Denmark Region, as previously described in detail $(5,6)$. In 2017-2018, the samples were used for measurement of maternal thyroid-stimulating hormone (TSH), free T4 (fT4), free T3 (fT3), total T4 (TT4), total T3 (TT3), and T-uptake on a Cobas 8000 (Roche Diagnostics, Basel, Switzerland), method A (6). Prior to these analyses, maternal TSH and fT4 had been measured in the same samples in 2015-2016 together with thyroid peroxidase antibodies (TPO-Ab) and thyroglobulin antibodies ( $\mathrm{Tg}-\mathrm{Ab}$ ) on an ADVIA Centaur XPT (Siemens Healthineers, Erlangen, Germany), method $B$ (5). In brief, all analyses were performed in routine hospital laboratories that were accredited according to DS/EN ISO 15189. All assays were validated prior to project initiation, and internal as well as external controls were included during the project period.

The biochemical measurements were linked to information in Danish nationwide health registers including the Medical Birth Register (MBR), the Danish National Hospital Register (DNHR), the Danish National Prescription Register (DNPR), and demographics available at Statistics Denmark. Information on maternal thyroid disease before, during, and after the pregnancy as well as diabetes was obtained from the combined use of hospital diagnoses in the DNHR and redeemed prescriptions assessed in the DNPR, as previously specified in detail (5, 16). Information on maternal age, gestational age, BMI, and smoking status was obtained from the MBR, which holds data on all births in Denmark (17). Thus, the MBR holds information on maternal height and pre-pregnancy body weight as well as smoking status in the first trimester of pregnancy including the number of cigarettes smoked per day.

This study included all live-birth pregnancies with measurement of maternal thyroid function in the early pregnancy using both biochemical methods $(n=5770)$. The selection of live births was required to obtain information

This work is licensed under a Creative Commons Attribution-NonCommercial-NoDerivatives 4.0 Internationad bicense.ifica.com at 04/26/2023 01:56:59AM 
on maternal BMI and smoking, and the first pregnancy in the study period was included to ensure that each woman participated only once. Pregnant women with missing information on BMI, smoking, or parity were excluded $(n=76)$. Also, women who reported smoking cessation $(n=85)$ were excluded because the date of smoking cessation in pregnancy was not registered. Finally, women who received medical treatment for thyroid disease in the early pregnancy $(n=77)$ and women with outlying thyroid function test results above the measurement range $(n=3)$ were excluded, leaving 5529 women in the study population.

Information on maternal height and pre-pregnancy weight was used to calculate pre-pregnancy BMI (body weight (in $\mathrm{kg}$ ) divided by the height (in $\left.\mathrm{m}^{2}\right)$ ). Concerning thyroid function tests, the free $\mathrm{T} 4 \mathrm{index}$ (ft4 index) was calculated as the TT4 divided by T-uptake. Individual T3/ T4 ratios were calculated including the TT3/TT4 ratio and the fT3/fT4 ratio. Maternal BMI and thyroid function test results showed non-normal distribution and were described by the median and the interquartile range. All thyroid function test results including the ratios were log-transformed prior to regression analyses. Multivariate linear regression was used to evaluate the association between categories of maternal BMI and smoking status in pregnancy, respectively, and continuous outcomes of the log-transformed thyroid function test results. Results of the regression analyses were back-transformed and reported as the geometric mean and the adjusted exponentiated beta coefficient $(a \beta)$. The $a \beta$ can be interpreted as the ratio of the outcome variable between the exposure and the reference group. The adjusted model included categorical variables (maternal BMI (<18.5 (underweight), 18.5-24.9 (normal weight), 25.0-29.9 (overweight), 30.0-34.9 (obesity), $\geq 35 \mathrm{~kg} / \mathrm{m}^{2}$ (severe obesity)); smoking (yes/no); parity (nulliparous/multiparous); origin (born in Denmark: yes/no); and diabetes (yes/no)) and continuous variables (maternal age and gestational week of blood sampling).

Possible interaction between maternal BMI and smoking was considered in a sub-analysis by the inclusion of an interaction term (BMI $\times$ smoking status) in the models. To evaluate a potential dose-dependent effect of maternal smoking, additional analyses were performed among smokers with information on the number of cigarettes smoked per day. Furthermore, stratified analyses were performed by gestational week of blood sampling (week 4-8, 9-11, and 12-14). In sensitivity analyses, the role of thyroid autoantibodies was investigated by additional adjustment for TPO- and $\mathrm{Tg}-\mathrm{Ab}$ as categorical variables (TPO-Ab positive (yes/no) defined by TPO-Ab above
$60 \mathrm{U} / \mathrm{mL}(n=540)$; $\mathrm{Tg}$-Ab positive (yes/no) defined by $\mathrm{Tg}-\mathrm{Ab}$ above $60 \mathrm{U} / \mathrm{mL}(n=540)$, as previously described in detail (16)). Furthermore, results were repeated when individuals diagnosed with thyroid disease before, during, or after the pregnancy were excluded $(n=161)$.

Results were reported with three significant digits, a $5 \%$ level of significance was chosen, and statistical analyses were performed using STATA version 16 (Stata Corp).

\section{Results}

Altogether, 5529 pregnant women were included in the study, and the blood samples were drawn in early pregnancy ranging from gestational week 4 to 14 with most samples around week 10 (Table 1). Most of the women (89.5\%) were born in Denmark, and nearly half (46.4\%) were expecting their first child. A summary of maternal thyroid function test results in the cohort showed that median TSH and fT4 were slightly lower with method B compared with method A (Table 1).

Overall, $56.0 \%$ of the pregnant women were classified as normal weight, $3.9 \%$ were underweight, and $40.1 \%$ of the women had a pre-pregnancy BMI at or above $25.0 \mathrm{~kg} / \mathrm{m}^{2}$ corresponding to adiposity (Table 2 ). Among women with adiposity, $24.4 \%$ were overweight, $10.3 \%$ were obese, and 5.4\% had severe obesity (Table 2). In total, 10.3\% of the women reported that they were smoking in the first trimester, and the frequency of smoking was dependent on maternal BMI. Thus, $19.9 \%$ of underweight women were smoking, whereas among women classified with adiposity, the frequency of maternal smoking was $11.6 \%$.

Table 1 Characteristics of the pregnant women in the study population $(n=5529)$.

\begin{tabular}{|c|c|c|}
\hline & Median & IQR \\
\hline Age (years) & 29.9 & $26.6-33.3$ \\
\hline $\mathrm{BMI}\left(\mathrm{kg} / \mathrm{m}^{2}\right)^{\mathrm{a}}$ & 23.9 & 21.4-27.5 \\
\hline Week of blood sampling & 10 & 9-11 \\
\hline \multicolumn{3}{|l|}{ Thyroid function tests } \\
\hline TSH (mIU/L) $)^{\mathrm{b}}$ & 1.18 & $0.724-1.80$ \\
\hline $\mathrm{TSH}(\mathrm{mlU} / \mathrm{L})^{\mathrm{c}}$ & 1.04 & $0.627-1.59$ \\
\hline Free T4 (pmol/L) $)^{b}$ & 16.6 & $15.3-18.0$ \\
\hline Free T4 $(\mathrm{pmol} / \mathrm{L})^{\mathrm{c}}$ & 16.2 & $15.0-17.6$ \\
\hline Free T4 index (nmol/L) $)^{b, d}$ & 113 & $100-126$ \\
\hline Total T4 (nmol/L) ${ }^{\mathrm{b}}$ & 127 & $112-144$ \\
\hline Total T3 (nmol/L) $)^{b}$ & 2.34 & $2.06-2.66$ \\
\hline Free T3 (pmol/L) & 5.05 & $4.70-5.47$ \\
\hline
\end{tabular}

${ }^{a}$ Calculated from pre-pregnancy weight and height. ${ }^{b}$ Method A (Cobas 8000, Roche Diagnostics). 'Method B (ADVIA Centaur XPT, Siemens Healthineers). ${ }^{\mathrm{d}}$ Calculated as total $\mathrm{T} 4$ divided by T-uptake.

$\mathrm{IQR}$, interquartile range; $\mathrm{TSH}$, thyroid-stimulating hormone; $\mathrm{T} 4$, thyroxine; T3, triiodothyronine. 


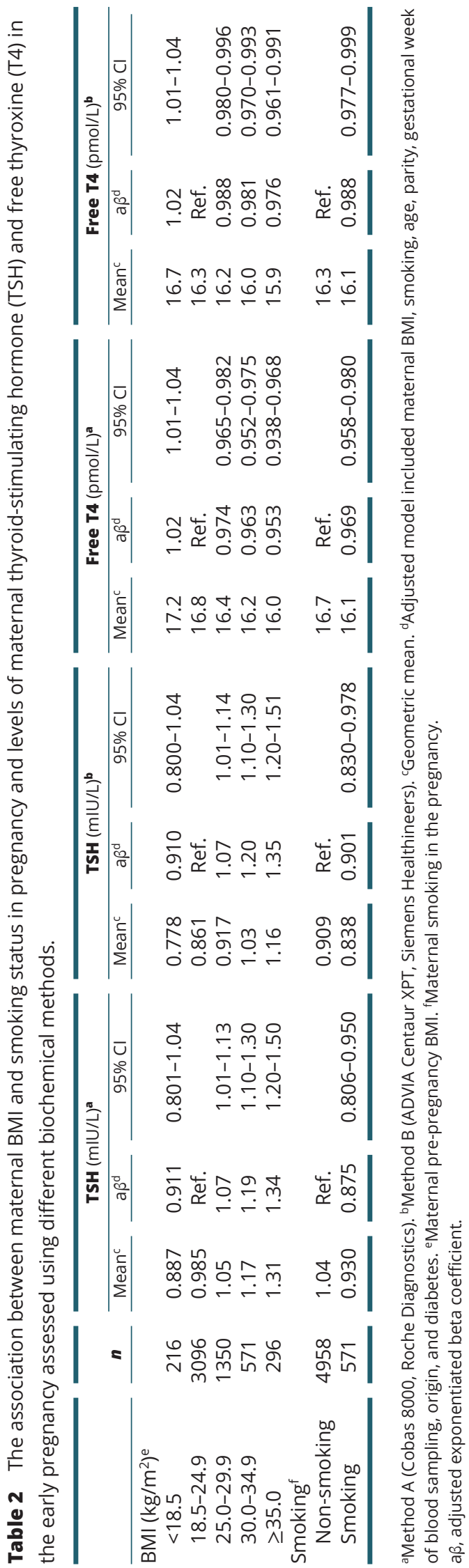

https://ec.bioscientifica.com https://doi.org/10.1530/EC-21-0376 (c) 2021 The authors Published by Bioscientifica Ltd
In multivariate regression, maternal BMI as well as smoking status were associated with the different measures of maternal thyroid function. Considering maternal TSH, underweight and smoking were associated with lower TSH, whereas adiposity was associated with higher TSH (Table 2). Increasing severity of maternal adiposity defined by increasingly higher BMI was associated with higher TSH, and this trend was similar regardless of the biochemical method used (Table 2). Considering measures of maternal T4, maternal adiposity and smoking were associated with lower fT 4 and fT 4 index (Tables 2 and 3 ) and smoking was associated with lower TT4, whereas no significant change in TT4 was seen for adiposity (Table 3). On the other hand, maternal underweight was associated with higher $\mathrm{fT} 4$ and higher $\mathrm{ft} 4$ index, but not with significant deviations in TT4. For measures of T3, maternal adiposity and smoking were associated with higher and underweight with lower fT3 and TT3.

When the measurements of T4 and T3 were used to calculate individual $\mathrm{T} 3 / \mathrm{T} 4$ ratios, maternal underweight was associated with lower ratios, whereas increasing severity of maternal adiposity was associated with increasingly higher ratios, and this trend was seen for measures of free and total thyroid hormones, respectively (Fig. 1). Maternal smoking was associated with higher T3/T4 ratios for free and for total thyroid hormones measures, but no dose-dependent effect was seen according to the reported number of cigarettes smoked per day (Fig. 2). When analyses were stratified by week of blood sampling in the early pregnancy, associations were seen within each stratum with no apparent trend by increasing gestational age (Table 4).

Overall, no interaction between maternal BMI and smoking status was seen in any of the models $(P>0.05$ for the interaction term). Results did not change when additionally adjusting for maternal TPO-Ab or Tg-Ab status or when women diagnosed with thyroid disease before, during, or after the pregnancy were excluded.

\section{Discussion}

\section{Principal findings}

In this large study of Danish pregnant women with comprehensive assessment of thyroid function in early pregnancy, maternal adiposity and smoking showed associations with a series of thyroid function tests. First, adiposity was associated with higher maternal TSH and a dose-dependent association with maternal BMI was seen. On the other hand, maternal smoking was associated with lower TSH. Secondly, both adiposity and smoking were associated with a higher maternal T3/T4

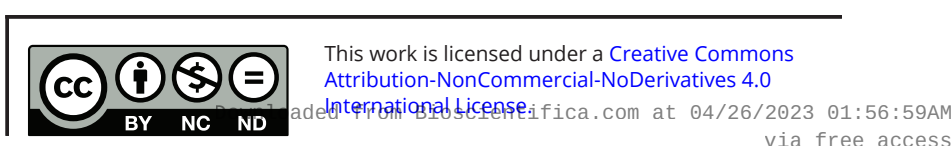




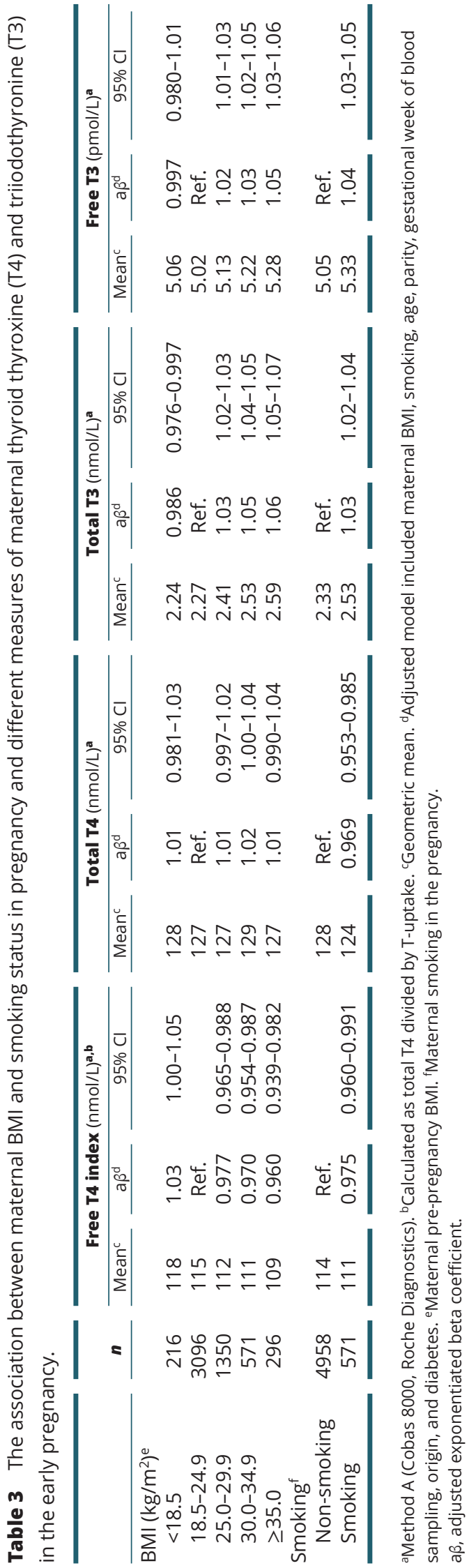

https://ec.bioscientifica.com https://doi.org/10.1530/EC-21-0376 (c) 2021 The authors Published by Bioscientifica Ltd ratio, and this finding was consistent irrespective of whether free or total thyroid hormone measurements were used. The associations observed in this clinical setting led to speculations on the underlying mechanisms. Furthermore, the robust associations between nonthyroidal maternal characteristics and thyroid function encourage considerations on the clinical implication.

\section{Interpretation}

A link between environmental exposures and thyroid disease has long been established (18). Historically, iodine intake was one of the most predominant environmental risk factors for thyroid disease, and population iodine intake is still a major determinant (19). The global implementation of iodine fortification programs has changed the occurrence and subtypes of thyroid disease in many countries. Meanwhile, there have been considerable lifestyle changes and a changing trend in other environmental risk factors. Adiposity and smoking are major health concerns. Although the frequency of smoking has declined, our data show that a significant proportion of pregnant women in Denmark were smoking one decade ago in line with global figures (11). Considering adiposity, the frequency is increasing worldwide, also in pregnant women, and more than one-third of the pregnant women in our cohort were overweight or obese (10).

The association among BMI, smoking, and thyroid diseasehaslongbeenconsidered.Onepartistheautoimmune origin of thyroid disease, and the interaction between environmental factors and autoimmune mechanisms (18). Another part is on thyroid function. In non-pregnant individuals, a positive association between BMI and levels of TSH has generally been seen, and a negative association with T4 was indicative of an association between adiposity and hypothyroidism (20). In contrast to these findings, a higher T3, and thereby a higher T3/T4 ratio, has been found in individuals with high BMI and a decrease in the ratio after weight loss (12). One hypothesis is that nutritional status affects deiodinase activity, in particular, the conversion of $\mathrm{T} 4$ to $\mathrm{T} 3$ via $\mathrm{D} 2$, and that adiposity increases D2 activity, which is reversed with weight loss (12). Another hypothesis is that the altered thyroid function in obese individuals may reflect a required central resistance to thyroid hormones, which may also be reversible with weight loss (21).

Our findings regarding maternal TSH, T3, and T4 in early pregnancy are consistent with findings in non-pregnant individuals and in pregnant women. All previous studies in pregnant women included the measurement of TSH, and different analytical platforms were used, but it varied between studies when the blood

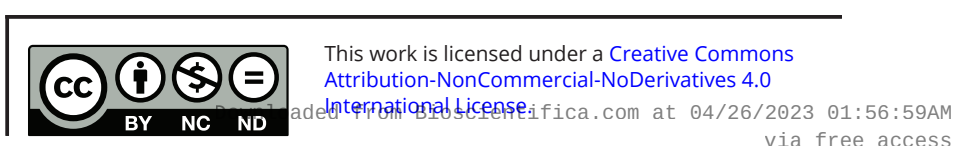




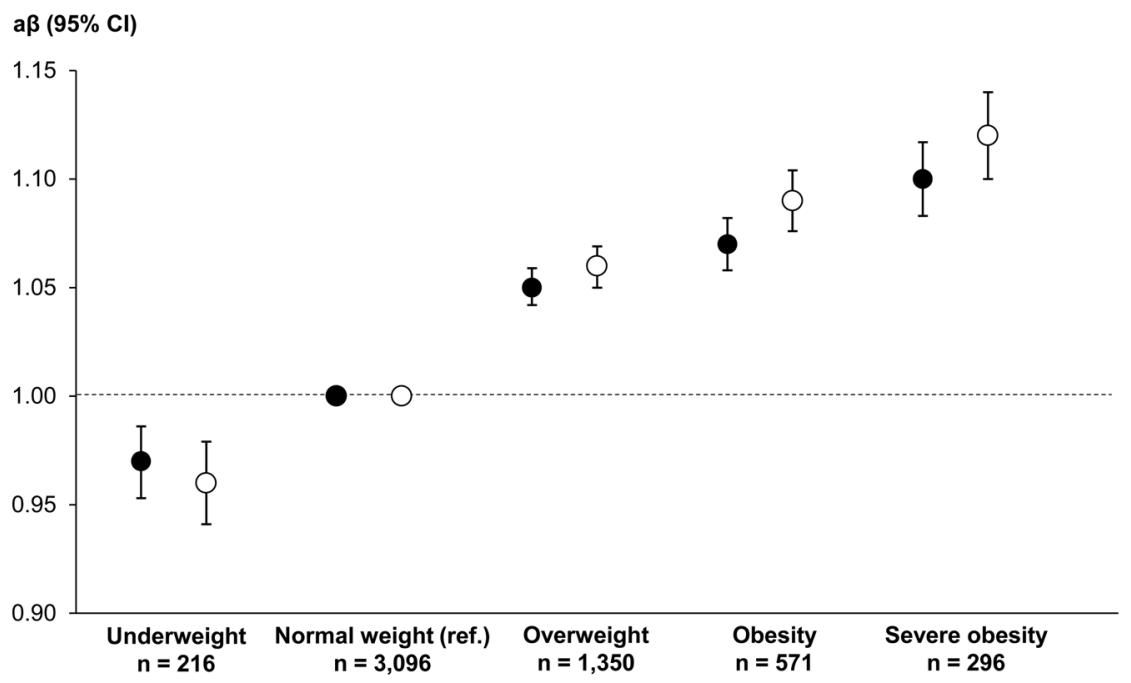

\begin{abstract}
Figure 1
Adjusted exponentiated beta coefficient $(a \beta)$ with 95\% Cl for maternal log-transformed triiodothyronine (T3)/thyroxine (T4) ratio stratified by maternal weight categories. The adjusted model included maternal age, parity, smoking, gestational week of blood sampling, origin, and diabetes. Measurements of T3 and T4 were performed using Method A (Cobas 8000, Roche Diagnostics), and filled circles illustrate the free T3/free T4 ratio, whereas open circles illustrate the total T3/total T4 ratio. Ref. indicates the reference group.
\end{abstract}

sample was drawn in pregnancy, whether T4 and/or T3 was measured, and whether total and/or free thyroid hormone measures were used (15, 22, 23, 24, 25, 26, 27, 28). Regardless of study differences, it was a consistent finding that higher maternal BMI was associated with higher TSH. Considering thyroid hormone levels, lower T4, higher T3, and higher T3/T4 ratio were the main findings associated with higher maternal BMI. Notably, we observed a negative association between maternal BMI and fT4, but no clear association with TT4. A few previous studies included measures of TT4 in addition to fT $4(25,28)$. One study found a negative association between BMI and levels of both fT4 and TT4 in early pregnancy (25), whereas another study found lower levels of fT4 and increasing levels of TT4 with higher maternal BMI (28). The conflicting results inspire speculations on the interplay with the physiological effects in pregnancy. The total thyroid hormone concentration increases from the early pregnancy in parallel with the increasing levels of TBG. In non-pregnant individuals, body fat mass and leptin levels were positively associated with TBG (29). Other binding proteins such as the sexual hormone binding globulin (SHBG) have been studied in obesity, and lower levels of SHBG were in general found in non-pregnant and in pregnant individuals (30). Following these lines of thought, we speculate whether the physiological alteration in TBG associated with pregnancy is influenced by maternal adiposity. Assessment of TBG in relation to BMI in pregnant women would be warranted to extend the findings.

Another physiological effect in pregnancy is the activity of the deiodinases, mainly D3 and D2, in placenta from the early pregnancy weeks $(7,8)$. The higher T3/T4 ratio observed in obese pregnant women in our study and in previous reports may be compatible with an increased activity of the D2 (15). Considering D3, the activity of this enzyme is high from the early pregnancy weeks as evident from a higher rT3/T3 ratio (3). One may speculate on the role of maternal adiposity in relation to the activity of D3 in early pregnancy, and how a combined effect of adiposity on D2 and D3

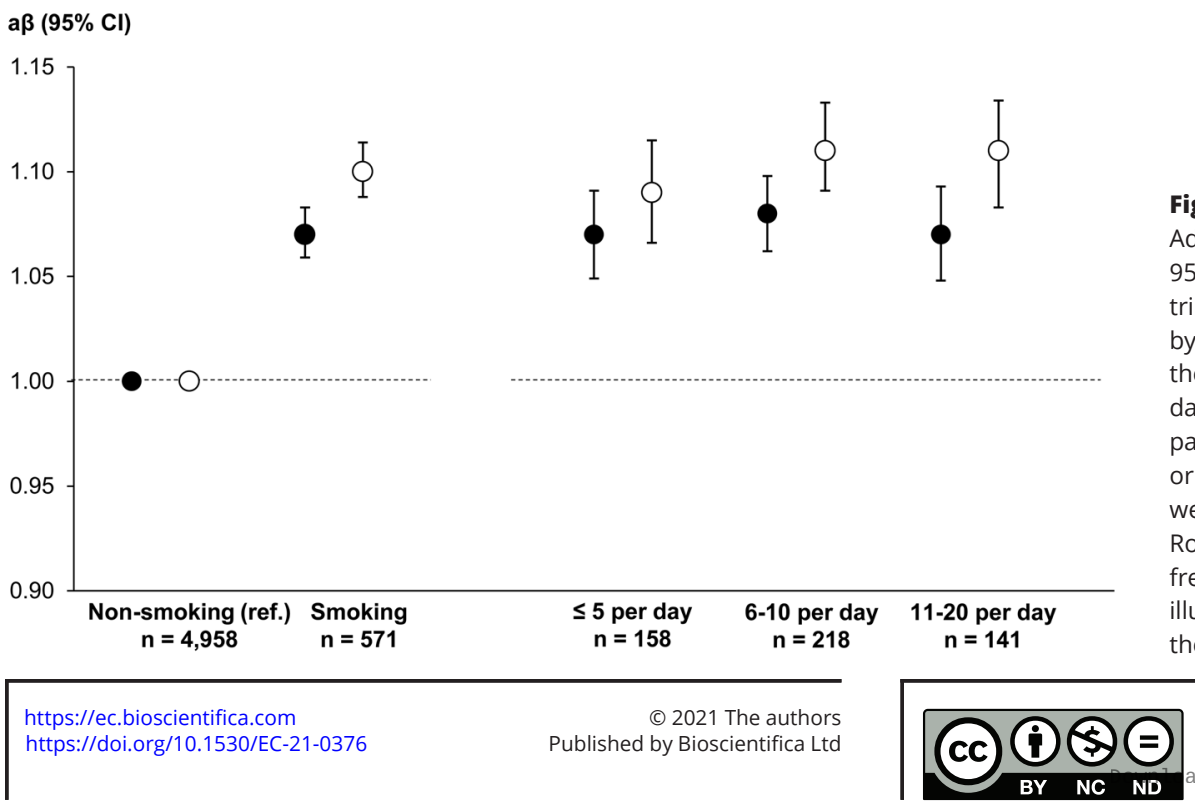

Figure 2

Adjusted exponentiated beta coefficient $(a \beta)$ with 95\% Cl for maternal log-transformed triiodothyronine (T3)/thyroxine (T4) ratio stratified by maternal smoking status in pregnancy and by the intensity of maternal smoking (cigarettes per day). The adjusted model included maternal age, parity, BMI, gestational week of blood sampling, origin, and diabetes. Measurements of T3 and T4 were performed using Method A (Cobas 8000, Roche Diagnostics), and filled circles illustrate the free T3/free T4 ratio, whereas open circles illustrate the total T3/total T4 ratio. Ref. indicates the reference group. https://ec.bioscientifica.com https://doi.org/10.1530/EC-21-0376
Published by Bioscientifica Ltd
This work is licensed under a Creative Commons Attribution-NonCommercial-NoDerivatives 4.0 elnternationab ficense.ifica com at 04/26/2023 01:56:59AM 
Table 4 The association between maternal BMI and smoking status in pregnancy and different measures of maternal triiodothyronine (T3)/thyroxine (T4) ratio stratified by week of pregnancy.

\begin{tabular}{|c|c|c|c|c|c|c|c|}
\hline & \multirow[b]{2}{*}{$n$} & \multicolumn{3}{|c|}{ Free $\mathrm{T} 3 /$ free $\mathrm{T} 4$ ratio $^{\mathrm{a}}$} & \multicolumn{3}{|c|}{ Total T3/total T4 ratioa } \\
\hline & & Mean $^{b}$ & $a \beta^{c}$ & $95 \% \mathrm{Cl}$ & Mean $^{b}$ & $a \beta^{c}$ & $95 \% \mathrm{Cl}$ \\
\hline \multicolumn{8}{|l|}{ BMI $\left(\mathrm{kg} / \mathrm{m}^{2}\right)^{\mathrm{d}}$} \\
\hline \multicolumn{8}{|l|}{ Week 4-8 } \\
\hline $18.5-24.9$ & 284 & 0.304 & Ref. & & 0.018 & Ref. & \\
\hline$\geq 25.0$ & 242 & 0.324 & 1.07 & $1.04-1.09$ & 0.020 & 1.07 & $1.04-1.09$ \\
\hline \multicolumn{8}{|l|}{ Week 9-11 } \\
\hline $18.5-24.9$ & 2492 & 0.298 & Ref. & & 0.018 & Ref. & \\
\hline$\geq 25.0$ & 1756 & 0.317 & 1.06 & $1.05-1.07$ & 0.019 & 1.07 & $1.06-1.08$ \\
\hline \multicolumn{8}{|l|}{ Week 12-14 } \\
\hline 18.5-24.9 & 320 & 0.298 & Ref. & & 0.018 & Ref. & \\
\hline$\geq 25.0$ & 219 & 0.321 & 1.07 & $1.04-1.09$ & 0.020 & 1.08 & $1.05-1.11$ \\
\hline \multicolumn{8}{|l|}{ Smokinge } \\
\hline \multicolumn{8}{|l|}{ Week 4-8 } \\
\hline Non-smoking & 472 & 0.301 & Ref. & & 0.019 & Ref. & \\
\hline Smoking & 73 & 0.329 & 1.05 & $1.02-1.09$ & 0.021 & 1.09 & $1.05-1.13$ \\
\hline \multicolumn{8}{|l|}{ Week 9-11 } \\
\hline Non-smoking & 3991 & 0.302 & Ref. & & 0.018 & Ref. & \\
\hline Smoking & 431 & 0.332 & 1.08 & $1.07-1.10$ & 0.020 & 1.11 & $1.09-1.13$ \\
\hline \multicolumn{8}{|l|}{ Week 12-14 } \\
\hline Non-smoking & 495 & 0.304 & Ref. & & 0.018 & Ref. & \\
\hline Smoking & 67 & 0.322 & 1.03 & 0.995-1.07 & 0.020 & 1.05 & $1.01-1.10$ \\
\hline
\end{tabular}

a Method A (Cobas 8000, Roche Diagnostics). 'beometric mean. 'Adjusted model included maternal BMI, smoking, age, parity, origin, and diabetes. ${ }^{\mathrm{d}}$ Maternal pre-pregnancy BMI. ${ }^{\mathrm{N}}$ Maternal smoking in the pregnancy.

$\mathrm{a} \beta$, adjusted exponentiated beta coefficient.

activity would be reflected in maternal thyroid function test results. Assessment of rT3 in relation to maternal BMI in pregnant women could extend the findings.

Another perspective on obesity is the link with diabetes. In non-pregnant individuals, T3 and TBG have been positively associated with glucose levels and insulin resistance (29). Similarly, the T3/T4 ratio was higher in pregnant women with gestational diabetes mellitus when evaluated at 24 and 32 weeks of gestation (15). The T3/T4 ratio correlated with $\mathrm{BMI}$ and with glucose and C-peptide levels in late pregnancy, and the authors speculated that a BMI-mediated increase in D2 activity in turn via elevated T3 levels may be a cause of higher glucose levels (15). In our study, we had information on maternal diagnosis of diabetes as a proxy for diabetes in pregnancy. We found robust associations between maternal BMI and the T3/T4 ratio after adjustment for diabetes, but further studies with biochemical assessment of maternal thyroid function and glucose levels in pregnancy would be of interest to enhance the understanding of the underlying mechanisms.

Considering smoking and thyroid function, lower TSH has generally been described in non-pregnant smoking individuals and often accompanied by an increase in both T4 and T3 (13). The association between smoking in pregnancy and maternal thyroid function has previously been investigated $(14,28,31)$. Most studies relied on self-reported information on maternal smoking status, but results were corroborated using cotinine measurements in one of the cohorts (28). Overall, the findings suggest lower $\mathrm{TSH}$, higher T3, and lower or unaltered T4 in smoking pregnant women compatible with a higher $\mathrm{T} 3 / \mathrm{T} 4$ ratio. It has been proposed that these findings reflect a smokingmediated effect on deiodinase activity (14), which may be more pronounced in pregnant women because of the parallel physiological effect. In non-pregnant individuals, the increase in T3 and T4 in smokers is proposed to reflect a smoking-induced activation of the sympathetic nervous system (13). Notably, pregnancy may have a physiological impact on the activity of the autonomic nervous system, and the balance of sympathetic to parasympathetic activity may change throughout pregnancy (32). In our study, we observed no dose-dependent effect of smoking, but a previous study found that maternal smoking history from the number of pack-years was associated with T4 and T3 in pregnancy (14). In this cohort, it was further found that women who quitted smoking in the pregnancy had lower T4 and higher T3, but higher TSH (14). The number of women who reported smoking cessation in pregnancy in our study was limited, and we could not address the timing of smoking cessation in relation to blood sampling.

Our study relied on an indirect assessment of exposure from maternal pre-pregnancy BMI and self-reported

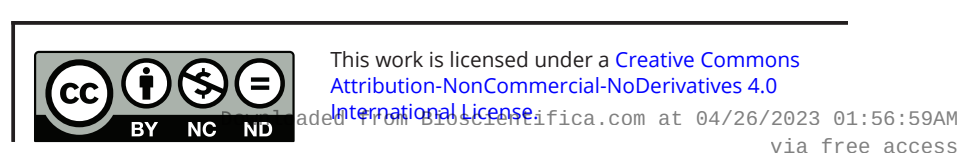


smoking habits. Information on maternal body weight in pregnancy was not available in the study population; however, pre-pregnancy BMI has been shown to correlate well with measured BMI and with BMI assessed in early pregnancy $(33,34)$. Considering smoking in pregnancy, self-reported information and cotinine levels have been shown to correlate but with a risk of underreporting active smoking and the smoking intensity (35). We acknowledge that stored blood samples were used for assessment of thyroid function tests including repeated measurements with different methods in the same samples. However, thyroid function parameters are in general considered stable for long-term storage and freezing and thawing (36).

\section{Implication}

Our results corroborate an association between maternal adiposity, smoking, and thyroid function in early pregnancy. The clinical findings support the hypothesis that these non-thyroidal maternal characteristics may alter deiodinase activity in pregnancy, particularly D2 activity, as reflected by a high T3/T4 ratio. However, the clinical and scientific implication of the associations remain uncertain as for the underlying mechanisms. It may be that the discrete alterations in thyroid hormone levels are not related to disorders of the thyroid gland but rather hormonal amendments in response to nonthyroidal aberrations. To this end, much focus has been on the role of smaller deviations in maternal thyroid function, e.g. hypothyroxinemia, in relation to adverse pregnancy outcomes (37). Following our line of thought, it may be speculated whether associations observed between smaller deviations in maternal thyroid function and adverse pregnancy outcomes may be confounded by other maternal characteristics such as adiposity and smoking, which independently are known risk factors for pregnancy complications $(3,4)$. Notably, treatment of smaller alterations in maternal thyroid function showed no effect in randomized controlled trials (38, 39). These studies' conclusions combined with the robust associations between maternal adiposity, smoking, and thyroid function are intriguing. An alternative to the focus on identifying and treating smaller thyroid function deviations may be to consider the impact of physiological non-thyroidal characteristics in the applied reference ranges for thyroid function tests to improve the diagnosis of actual thyroid disease. Further studies that address the role of maternal non-thyroidal characteristics in relation to thyroid function in pregnancy are warranted to inform the debate.

\section{Declaration of interest}

The authors declare that there is no conflict of interest that could be perceived as prejudicing the impartiality of the research reported.

\section{Funding}

This work was supported by the Novo Nordisk Foundation (grant number: NNF200C0059465).

\section{Author contribution statement}

$S \mathrm{~L}$ A conceptualized the study, performed the data analyses, and drafted the manuscript. L K, A H, P V, and S A critically reviewed and commented on the manuscript.

\section{References}

1 Lazarus J, Brown RS, Daumerie C, Hubalewska-Dydejczyk A, Negro R \& Vaidya B. European thyroid association guidelines for the management of subclinical hypothyroidism in pregnancy and in children. European Thyroid Journal 20143 76-94. (https://doi.org/10.1159/000362597)

2 Alexander EK, Pearce EN, Brent GA, Brown RS, Chen H, Dosiou C, Grobman WA, Laurberg P, Lazarus JH, Mandel SJ, et al. 2017 Guidelines of the American Thyroid Association for the diagnosis and management of thyroid disease during pregnancy and the postpartum. Thyroid 201727 315-389. (https://doi.org/10.1089/thy.2016.0457)

3 Laurberg P, Andersen SL, Pedersen IB, Andersen S \& Carle A. Screening for overt thyroid disease in early pregnancy may be preferable to searching for small aberrations in thyroid function tests. Clinical Endocrinology 201379 297-304. (https://doi.org/10.1111/cen.12232)

4 Andersen SL \& Andersen S. Turning to thyroid disease in pregnant women. European Thyroid Journal 20209 225-233. (https://doi. org/10.1159/000506228)

5 Andersen SL, Andersen S, Carlé A, Christensen PA, Handberg A, Karmisholt J, Knøsgaard L, Kristensen SR, Bülow Pedersen I \& Vestergaard P. Pregnancy week-specific reference ranges for thyrotropin and free thyroxine in the north Denmark region pregnancy cohort. Thyroid 201929 430-438. (https://doi.org/10.1089/thy.2018.0628)

6 Andersen SL, Christensen PA, Knøsgaard L, Andersen S, Handberg A, Hansen AB \& Vestergaard P. Classification of thyroid dysfunction in pregnant women differs by analytical method and type of thyroid function test. Journal of Clinical Endocrinology and Metabolism 2020105 1-11. (https://doi.org/10.1210/clinem/dgaa567)

7 Bianco AC, Salvatore D, Gereben B, Berry MJ \& Larsen PR. Biochemistry, cellular and molecular biology, and physiological roles of the iodothyronine selenodeiodinases. Endocrine Reviews 200223 38-89. (https://doi.org/10.1210/edrv.23.1.0455)

8 Chan S, Kachilele S, Hobbs E, Bulmer JN, Boelaert K, McCabe CJ, Driver PM, Bradwell AR, Kester M, Visser TJ, et al. Placental iodothyronine deiodinase expression in normal and growth-restricted human pregnancies. Journal of Clinical Endocrinology and Metabolism 200388 4488-4495. (https://doi.org/10.1210/jc.2003-030228)

9 Araujo RL \& Carvalho DP. Bioenergetic impact of tissue-specific regulation of iodothyronine deiodinases during nutritional imbalance. Journal of Bioenergetics and Biomembranes 201143 59-65. (https://doi.org/10.1007/s10863-011-9327-x)

10 NCD Risk Factor Collaboration. Trends in adult body-mass index in 200 countries from 1975 to 2014: a pooled analysis of 1698 populationbased measurement studies with 19.2 million participants. Lancet 2016 387 1377-1396. (https://doi.org/10.1016/S0140-6736(16)30054-X)

11 Lange S, Probst C, Rehm J \& Popova S. National, regional, and global prevalence of smoking during pregnancy in the general population: a systematic review and meta-analysis. Lancet Global Health 20186 e769-e776. (https://doi.org/10.1016/S2214-109X(18)30223-7) 
12 Agnihothri RV, Courville AB, Linderman JD, Smith S, Brychta R, Remaley A, Chen KY, Simchowitz L \& Celi FS. Moderate weight loss is sufficient to affect thyroid hormone homeostasis and inhibit its peripheral conversion. Thyroid 201424 19-26. (https://doi.org/10.1089/ thy.2013.0055)

13 Wiersinga WM. Smoking and thyroid. Clinical Endocrinology 201379 145-151. (https://doi.org/10.1111/cen.12222)

14 Mannisto T, Hartikainen AL, Vaarasmaki M, Bloigu A, Surcel HM, Pouta A, Jarvelin MR, Ruokonen A \& Suvanto E. Smoking and early pregnancy thyroid hormone and anti-thyroid antibody levels in euthyroid mothers of the northern Finland birth cohort 1986. Thyroid 201222 944-950. (https://doi.org/10.1089/thy.2011.0377)

15 Haddow JE, Metzger BE, Lambert-Messerlian G, Eklund E, Coustan D, Catalano P \& Palomaki GE. Maternal BMI, peripheral deiodinase activity, and plasma glucose: relationships between white women in the HAPO study. Journal of Clinical Endocrinology and Metabolism 2019 104 2593-2600. (https://doi.org/10.1210/jc.2018-02328)

16 Knøsgaard L, Andersen S, Hansen AB, Vestergaard P \& Andersen SL. Thyroid function abnormalities and thyroid autoantibodies in Danish pregnant women. Clinical Endocrinology 202093 329-338. (https:// doi.org/10.1111/cen.14147)

17 Bliddal M, Broe A, Pottegård A, Olsen J \& Langhoff-Roos J. The Danish medical birth register. European Journal of Epidemiology 201833 27-36. (https://doi.org/10.1007/s10654-018-0356-1)

18 Brent GA. Environmental exposures and autoimmune thyroid disease. Thyroid 201020 755-761. (https://doi.org/10.1089/thy.2010.1636)

19 Laurberg P, Cerqueira C, Ovesen L, Rasmussen LB, Perrild H, Andersen S, Pedersen IB \& Carle A. Iodine intake as a determinant of thyroid disorders in populations. Best Practice and Research: Clinical Endocrinology and Metabolism 201024 13-27. (https://doi.org/10.1016/j.beem.2009.08.013)

20 Laurberg P, Knudsen N, Andersen S, Carlé A, Pedersen IB \& Karmisholt J. Thyroid function and obesity. European Thyroid Journal 20121 159-167. (https://doi.org/10.1159/000342994)

21 Juiz-Valiña P, Cordido M, Outeiriño-Blanco E, Pértega S, VarelaRodríguez BM, García-Brao MJ, Mena E, Pena-Bello L, SangiaoAlvarellos S \& Cordido F. Central resistance to thyroid hormones in morbidly obese subjects is reversed after bariatric surgery-induced weight loss. Journal of Clinical Medicine 20209 359. (https://doi. org/10.3390/jcm9020359)

22 Pop VJ, Biondi B, Wijnen HA, Kuppens SM \& Lvader H. Maternal thyroid parameters, body mass index and subsequent weight gain during pregnancy in healthy euthyroid women. Clinical Endocrinology 201379 577-583. (https://doi.org/10.1111/cen.12177)

23 Knight BA, Shields BM, Hattersley AT \& Vaidya B. Maternal hypothyroxinaemia in pregnancy is associated with obesity and adverse maternal metabolic parameters. European Journal of Endocrinology 2016174 51-57. (https://doi.org/10.1530/EJE-15-0866)

24 Bassols J, Prats-Puig A, Soriano-Rodríguez P, García-González MM, Reid J, Martínez-Pascual M, Mateos-Comerón F, Zegher F De, Ibáñez L \& López-Bermejo A. Lower free thyroxin associates with a less favorable metabolic phenotype in healthy pregnant women. Journal of Clinical Endocrinology and Metabolism 201196 3717-3723. (https://doi. org/10.1210/jc.2011-1784)

25 Mosso L, Martinez A, Rojas MP, Latorre G, Margozzini P, Lyng T, Carvajal J, Campusano C, Arteaga E \& Boucai L. Early pregnancy thyroid hormone reference ranges in Chilean women: the influence of body mass index. Clinical Endocrinology 201685 942-948. (https://doi. org/10.1111/cen.13127)

26 Kahr MK, Antony KM, Delbeccaro M, Hu M, Aagaard KM \& Suter MA. Increasing maternal obesity is associated with alterations in both maternal and neonatal thyroid hormone levels. Clinical Endocrinology 201684 551-557. (https://doi.org/10.1111/cen.12974)
27 Collares FM, Korevaar TIM, Hofman A, Steegers EAP, Peeters RP, Jaddoe VWV \& Gaillard R. Maternal thyroid function, prepregnancy obesity and gestational weight gain-the generation R study: a prospective cohort study. Clinical Endocrinology 201787 799-806. (https://doi.org/10.1111/cen.13412)

28 Derakhshan A, Shu H, Broeren MAC, Poortere RA de, Wikstrom S, Peeters RP, Demeneix B, Bornehag CG \& Korevaar TIM. Reference ranges and determinants of thyroid function during early pregnancy: the SELMA study. Journal of Clinical Endocrinology and Metabolism 2018 103 3548-3556. (https://doi.org/10.1210/jc.2018-00890)

29 Roef G, Lapauw B, Goemaere S, Zmierczak HG, Toye K, Kaufman JM $\&$ Taes Y. Body composition and metabolic parameters are associated with variation in thyroid hormone levels among euthyroid young men. European Journal of Endocrinology 2012167 719-726. (https://doi. org/10.1530/EJE-12-0447)

30 Faal S, Abedi P, Jahanfar S, Ndeke JM, Mohaghegh Z, Sharifipour F $\&$ Zahedian M. Sex hormone binding globulin for prediction of gestational diabetes mellitus in pre-conception and pregnancy: a systematic review. Diabetes Research and Clinical Practice 2019152 39-52. (https://doi.org/10.1016/j.diabres.2019.04.028)

31 Shields B, Hill A, Bilous M, Knight B, Hattersley AT, Bilous RW \& Vaidya B. Cigarette smoking during pregnancy is associated with alterations in maternal and fetal thyroid function. Journal of Clinical Endocrinology and Metabolism 200994 570-574. (https://doi. org/10.1210/jc.2008-0380)

32 Kuo CD, Chen GY, Yang MJ, Lo HM \& Tsai YS. Biphasic changes in autonomic nervous activity during pregnancy. British Journal of Anaesthesia 200084 323-329. (https://doi.org/10.1093/oxfordjournals. bja.a013433)

33 Han E, Abrams B, Sridhar S, Xu F \& Hedderson M. Validity of selfreported pre-pregnancy weight and body mass index classification in an integrated health care delivery system. Paediatric and Perinatal Epidemiology 201630 314-319. (https://doi.org/10.1111/ppe.12286)

34 Natamba BK, Sanchez SE, Gelaye B \& Williams MA. Concordance between self-reported pre-pregnancy body mass index (BMI) and BMI measured at the first prenatal study contact. BMC Pregnancy and Childbirth 201616 1-8. (https://doi.org/10.1186/s12884-016-0983-z)

35 Lindqvist R, Lendahls L, Tollbom O, Åberg H \& Håkansson A. Smoking during pregnancy: comparison of self-reports and cotinine levels in 496 women. Acta Obstetricia et Gynecologica Scandinavica 200281 240-244. (https://doi.org/10.1034/j.1600-0412.2002.810309.x)

36 Mannisto T, Surcel HM, Bloigu A, Ruokonen A, Hartikainen AL, Jarvelin MR, Pouta A, Vaarasmaki M \& Suvanto-Luukkonen E. The effect of freezing, thawing, and short- and long-term storage on serum thyrotropin, thyroid hormones, and thyroid autoantibodies: implications for analyzing samples stored in serum banks. Clinical Chemistry 200753 1986-1987. (https://doi.org/10.1373/ clinchem.2007.091371)

37 Dosiou C \& Medici M. Management of endocrine disease: isolated maternal hypothyroxinemia during pregnancy: knowns and unknowns. European Journal of Endocrinology 2017 176 R21-R38. (https://doi.org/10.1530/EJE-16-0354)

38 Lazarus JH, Bestwick JP, Channon S, Paradice R, Maina A, Rees R, Chiusano E, John R, Guaraldo V, George LM, et al. Antenatal thyroid screening and childhood cognitive function. New England Journal of Medicine 2012366 493-501. (https://doi.org/10.1056/ NEJMoa1106104)

39 Casey BM, Thom EA, Peaceman AM, Varner MW, Sorokin Y, Hirtz DG, Reddy UM, Wapner RJ, Thorp Jr JM, Saade G, et al. Treatment of subclinical hypothyroidism or hypothyroxinemia in pregnancy. New England Journal of Medicine 2017376 815-825. (https://doi. org/10.1056/NEJMoa1606205)

Received in final form 29 July 2021

Accepted 17 August 2021

Accepted Manuscript published online 19 August 2021 https://ec.bioscientifica.com https://doi.org/10.1530/EC-21-0376 (c) 2021 The authors Published by Bioscientifica Ltd

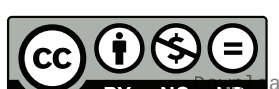

This work is licensed under a Creative Commons Attribution-NonCommercial-NoDerivatives 4.0 International License ifica com at $04 / 26 / 202301: 56: 594$ M 